Original Research

\title{
Spatio-temporal clusters of incident human brucellosis cases in Ecuador
}

\author{
Lenin Ron ${ }^{\mathrm{a}, \mathrm{b}, \mathrm{c}}$, Washington Benitez ${ }^{\mathrm{a}}$, Niko Speybroeck ${ }^{\mathrm{d}}$, Jorge Ron ${ }^{\mathrm{a}}$, Claude Saegerman ${ }^{\mathrm{c}}$, \\ Dirk Berkvens ${ }^{\mathrm{b}}$, Emmanuel Abatih ${ }^{\mathrm{b}, *}$ \\ ${ }^{a}$ Centro Internacional de Zoonosis (CIZ), P.O. Box: 17-03-100, Geronimo Leyton SN y Gato Sobral, Ciudadela Universitaria, Quito, Ecuador \\ ${ }^{\mathrm{b}}$ Unit of Epidemiology, Department of Biomedical Sciences, Institute of Tropical Medicine, Nationalestraat 155, 2000 Antwerpen, Belgium \\ ${ }^{\mathrm{c}}$ Research Unit of Epidemiology and Risk Analysis Applied to Veterinary Sciences (UREAR-ULg), Department of Infectious and Parasitic Diseases, \\ Faculty of Veterinary Medicine, University of Liege, Boulevard de Colonster 20, B42, B-4000 Liege, Belgium \\ ${ }^{\mathrm{d}}$ Institute of Health and Society, Université Catholique de Louvain, Clos Chapelle-aux-champs 30, 1200 Woluwe-Saint-Lambert, Brussels, Belgium
}

\section{A R T I C L E I N F O}

\section{Article history:}

Received 13 May 2012

Revised 18 January 2013

Accepted 12 February 2013

Available online 19 Feb 2013

\section{Keywords:}

Brucellosis

Humans

Ecuador

Zero-inflated Poisson regression

Spatio-temporal distribution

\begin{abstract}
A B S T R A C T
This study aimed to determine whether variations in the incidence of reported cases of human brucellosis in Ecuador were clustered in space and time. In addition, the effects of cattle and small ruminant population density and other socio-economic factors on the incidence were investigated. Significant space-time clusters were found in the northern and southern highlands and parts of Ecuadorian Amazonia. Customs of people, cattle, goat and sheep population density appeared to influence the incidence of brucellosis. In this study, the incidence of reported cases of human brucellosis was found to be higher in the highlands (sierra) and in municipalities near Peru and Colombia. The results of this study highlight the need for prevention and control measures aimed at abating the incidence of brucellosis among livestock and humans.
\end{abstract}

(c) 2013 Elsevier Ltd. All rights reserved.

\section{Introduction}

Brucellosis is one of the world's major zoonoses (Pappas et al., 2005). Four Brucella species are mainly responsible for the disease: Brucella abortus typically found in cattle; Brucella melitensis in goats and sheep; Brucella suis in swine; and Brucella canis in dogs (Fosgate et al., 2002; Sauret and Vilissova, 2002). Even though these four species of Brucella can infect humans; B. melitensis has been mentioned as the most pathogenic and frequent in humans (Lucero et al., 2008). Humans contract the disease through consumption of infected and unpasteurized milk and milk products, through direct contact with infected tissues such as placenta and through inhalation of infected aerosolized particles (Pappas et al., 2005). Human brucellosis is associated with chronic debilitating infections and is often

\footnotetext{
* Corresponding author. Tel.: +32 3 2476392; fax: +32 32476268 .

E-mail address: enjiabatih@itg.be (E. Abatih).
}

characterized by fever of unknown origin, a less specific symptom (Sauret and Vilissova, 2002; Almuneef et al., 2004; Martins et al., 2009).

Brucellosis in cattle and in small ruminants remains a significant animal health problem in many countries (Sauret and Vilissova, 2002; Anonymous, 2005; D'Orazi et al., 2007; Martins et al., 2009). The disease mainly affects reproduction and fertility in females, thereby reducing survival of newborns, and reducing milk yield (Sewell and Brocklesby, 1990; Zinsstag et al., 2005). In industrialized countries, effective control measures are implemented for eradication, including intensive national surveillance systems in animals and removal of infected livestock (Pappas et al., 2005; Lithg-Pereira et al., 2004; Yamamoto et al., 2008; Lee et al., 2009). However, developing countries rarely have national programs to prevent, control, monitor and eradicate brucellosis in animal populations.

Ecuador, with nearly 5 million cattle, 1.2 million sheep, 1.7 million pigs, and 0.15 million goats has no structured 
system for livestock disease management. Slaughterhouses and National Veterinary Service reports frequently include foot and mouth disease cases, distomatosis, metritis, and mastitis in cattle, goats, sheep and pigs that are slaughtered (Anonymous, 2008a). The seroprevalence of bovine brucellosis was officially estimated to range from $1.92 \%$ to $10.62 \%$ among the provinces in the highlands (Sierra) and from $4.12 \%$ to $10.62 \%$ among provinces in the Coast (Torres, 2008). The seroprevalence of bovine brucellosis was estimated to be $2.17 \%$ and $9.42 \%$ using the Rose Bengal Test (RBT) and indirect Enzyme-linked immunosorbent assay (iELISA), respectively in Santo Domingo (Pichincha) and $1.08 \%$ and $9.73 \%$ respectively in El Carmen (Manabí) (Angulo and Tufiño, 2005). Furthermore, in Ecuador, an average of 12 hospitalized human brucellosis cases are reported through the National Office of Statistics every year (Anonymous, 2006).

A Study carried out among farmers in Peru (bordering country of Ecuador) have estimated a brucellosis seroprevalence to be between $1.5 \%$ and $4.5 \%$ in humans (MendozaNúñez et al., 2008), and a pilot study conducted in the northern part of Ecuador estimated a true prevalence between $24 \%$ and $48 \%$ in cattle (Ron-Roman, 2003). In both studies, the consumption of unpasteurized milk and milk products, permanent contact with animals, and the occupation of the people were the main factors found to be associated with brucellosis seropositivity among humans. The identification of the municipality and time period with an elevated risk of the infection may contribute to our understanding of the underlying risk factors for the disease. For example, the results of comparing and contrasting clusters with information on the population density of livestock or on the ethnic groups in the population may be used to explain observed clusters (Fosgate et al., 2002; DeChello and Sheehan, 2007).

The aim of this study was to determine the spatio-temporal distribution of incident human brucellosis cases in the continental Ecuadorian territory using municipality level data on reported cases of human brucellosis between 1996 and 2008. This will enable the identification of areas with a high incidence of the disease and also to assess the effects of important risk factors such as ethnicity and cattle, sheep and goat population densities on the space-time distribution of the disease.

\section{Materials and methods}

\subsection{Study region and data}

The study unit was the municipality. In Ecuador, after the province, the municipality is the second level of political administration. Information on the number of incident human cases of brucellosis and total human population between 1996 and 2008 for each municipality was provided by the National Office of Statistics (Anonymous, 2006). It was assumed that all cases originated at patients municipality of residence. Brucellosis cases were identified based on presumptive clinical diagnosis. The map showing the political division of the country at municipality level was provided by the agricultural office of geographical infor- mation systems (Anonymous, 2007). Since the data were aggregated at the municipality level, each record was designed to contain the total number of reported human cases, the population, the year and the coordinates of the centroid of each municipality. In addition, the number of cattle, goats, sheep, and swine population by municipality were collected for each year. Information was also available for some potential municipality level risk factors for the presence of human brucellosis: climatic zone (tropical or highlands), percentage of farms with technical assistance (fraction of the number of farms which were visited by veterinarians or agronomist), number of people in the municipality, percentage of indigenous people in each municipality, percentage of grazing land in the municipality, proportion of farms with artificial irrigation in the municipality, percentage of households with tubing water, percebtage of people living in extreme poverty and literacy level in the municipality (Anonymous, 2008b).

The study was reviewed and approved by the ethical committee of the Biomedical Center of the Central University of Ecuador (COBI/CBM/UCE).

\subsection{Zero-inflated Poisson regression model}

The data used for this study are reported cases of incident human brucellosis based on hospital records of clinically diagnosed patients and risk factors at municipality level were obtained from national databases. For most of the municipalities, no human brucellosis cases were reported. Therefore, use of the Poisson and negative binomial regression models on this type of data may lead to biased estimations as they do not take account of the overabundance of zeros. To overcome these drawbacks, zero-inflated Poisson (ZIP) models first proposed by Lambert (Lambert, 1992) can be used. The ZIP model accounts for excess zeros by distinguishing between two types of zeros namely structural and random. For the data at hand, structural (true) zeros arose in municipalities where individuals were not predisposed to brucellosis for example not consuming unpasteurized milk products or not involved in occupations that increase their risk of acquiring brucellosis. Random (false) zeros on the other hand are believed to have arisen from confusing brucellosis symptoms with those of other health problems, not seeking treatment due to lack of hospitals or because individuals though subject to activities that expose them to the infection are not infected. To determine which of the ZIP and zero-inflated negative binomial models (ZINB) models best fits the observed data, both models were fit to the data with no covariates and the expected counts were obtained. The model with the fitted counts closest to the observed counts was selected as the most appropriate model to start with (Zaninotto and Falaschetti, 2011).

To assess the influence of the selected risk factors (Section 2.1) on the incidence of reported cases of incident human brucellosis, the ZIP (or ZINB) model models the nonzero counts and those that can be expected under a Poisson model using a Poisson distribution (or Negative Binomial distribution) and the zero counts using a logistic regression model to model the probability of a municipality being in the structural zero group (Long and Freese, 2001). A man- 
ual forward stepwise model building approach was employed with the Akaike's Information Criterion (AIC) as the calibrating parameter to select the final model. Finally, Vuong's test was used to determine whether the ZIP (ZINB) model performed better than a standard Poisson regression model (Negative binomial model). A significant $p$-value of this test will indicate that the ZIP (or ZINB) model provides a better fit (Long and Freese, 2001). The models were built using the zip command in STATA, version 12, software (SataCorp LP, College Station, Texas).

\subsection{Regression tree analysis}

In addition to the zero-inflated Poisson model, Poisson regression tree analysis (Rosicova et al., 2011) was used to explore the effects of potential socio-economic variables and their interactions on reported brucellosis cases within municipalities. The response variable of interest in this case was the number of brucellosis cases combined with the total population ( 2 columns matrix) and the explanatory variables used are listed in Section 2.1. The process of tree building involves determining, for each node, which of the many possible splits best explains the variability in brucellosis incidence risk, and then deciding whether a node should be terminal or should be further split into sub nodes (Breiman, 1984). Pruning was applied to obtain a simpler tree in which the splits significantly reduced the variability within subgroups. The $R$ software ( $R$ version 2.10.1) package rpart was used with Poisson method as splitting criterion and for generating the trees (Terneau and Atkinson, 1997).

\subsection{Space-time analysis}

The space-time scan software (Kulldorf, 1997) was used to search, test for significance and identify approximate locations of areas with an increased risk for the occurrence of human brucellosis cases. The search for significant space-time clusters was performed using cylindrical moving windows of variable sizes that moved in space and in time across the study region. The circular base of the cylinder represented the spatial dimension and varied from 0 up to a specified maximum value which allowed for the inclusion of as much as $50 \%, 25 \%$ and $10 \%$ of the total number of centroids in the study region respectively. The height of the cylinder represented the temporal dimension with a maximum of up to $50 \%$ of the study period with a time precision of 1 year. Assuming for each cylinder that cases were Poisson-distributed, space-time clustering was assessed by comparing the incidence risk of brucellosis within the cylinder with the risk expected if brucellosis cases were randomly distributed in space and time. The likelihood ratio for each cluster was calculated based on the number of cases inside and outside the cylinder. The cylinder with the maximum likelihood ratio was selected as the most likely cluster. The significance of identified space-time clusters was tested using the likelihood ratio test statistic and $p$-values of the test were obtained through Monte Carlo simulations. In this study, 999 simulations were used and significance was arbitrated at the $5 \%$ level. Only secondary clusters that do not overlap with the most likely cluster were requested from the SaTScan Software. It is worth noting that, it is possible to detect smaller sized clusters when the maximum scanning window is set at $50 \%$ if they have a greater likelihood. The smaller sized windows were therefore applied to explore more localized clusters by eliminating larger clusters which could have a higher likelihood ratio. The resulting space-time clusters were contrasted with raster geographic data of livestock density in municipalities found in Geonetwotk generated by the FAO-AGRA project (Anonymous, 2009). All significant clusters were visualized using Manifold System (version 8) (CDA International Ltd.).

\section{Results}

A total of 163 reported cases of human brucellosis between 1996 and 2008 in the 217 municipalities of Ecuador were analyzed. One case reported in Galapagos Islands in 2002 was not included in the analysis since the island is detached from the national territory and because with one case alone, a separate analysis for the island could not be done. Fig. 1 shows the reported incidence risk of human brucellosis between 1996 and 2008 for Ecuador. Overall, the reported incidence risk of brucellosis was observed to vary across the years with peaks in 1996, 2000 and 2007. In addition, a steeply increasing trend was observed from 2002 to 2007.

The plot of the distribution of the observed and expected counts revealed that the ZINB was underestimating the number of excess zeros and over estimating the number of 1's whereas the ZIP model provided expected counts closer to the observed number of reported human brucellosis cases (Fig. 2). The ZIP model was therefore considered during the model building process. Vuong's test suggested that the ZIP model performed better than the standard Poisson regression model $(Z=3.59, p$-value $<0.001)$. Based on the final model, the number of cattle, the number of sheep, the number of goats and the climatic zone (tropical or highlands) had significant relationships with the incidence of reported cases of human brucellosis and no significant relationships with the probability of not having human brucellosis (Table 1 ).

It can be seen from the results that whereas the number of sheep; number of goats and the climatic zone or origin of the cases had significant effects on the expected incidence of reported human brucellosis cases, they had no influence on the probability of the absence of human brucellosis. On the other hand, the number of cattle seemed to influence both the presence of human brucellosis and the probability of its absence. However, the coefficient is positive for the count model part and negative for the logistic regression model part. This is an indication that an increase in the number of cattle is associated with a corresponding increase in the expected incidence of human brucellosis whereas an increase in the number of cattle leads to a decrease in the odds of a municipality not having human brucellosis.

Among the municipalities that were exposed to brucellosis, the expected incidence of reported cases of human brucellosis was 1.64 times higher for those municipalities 


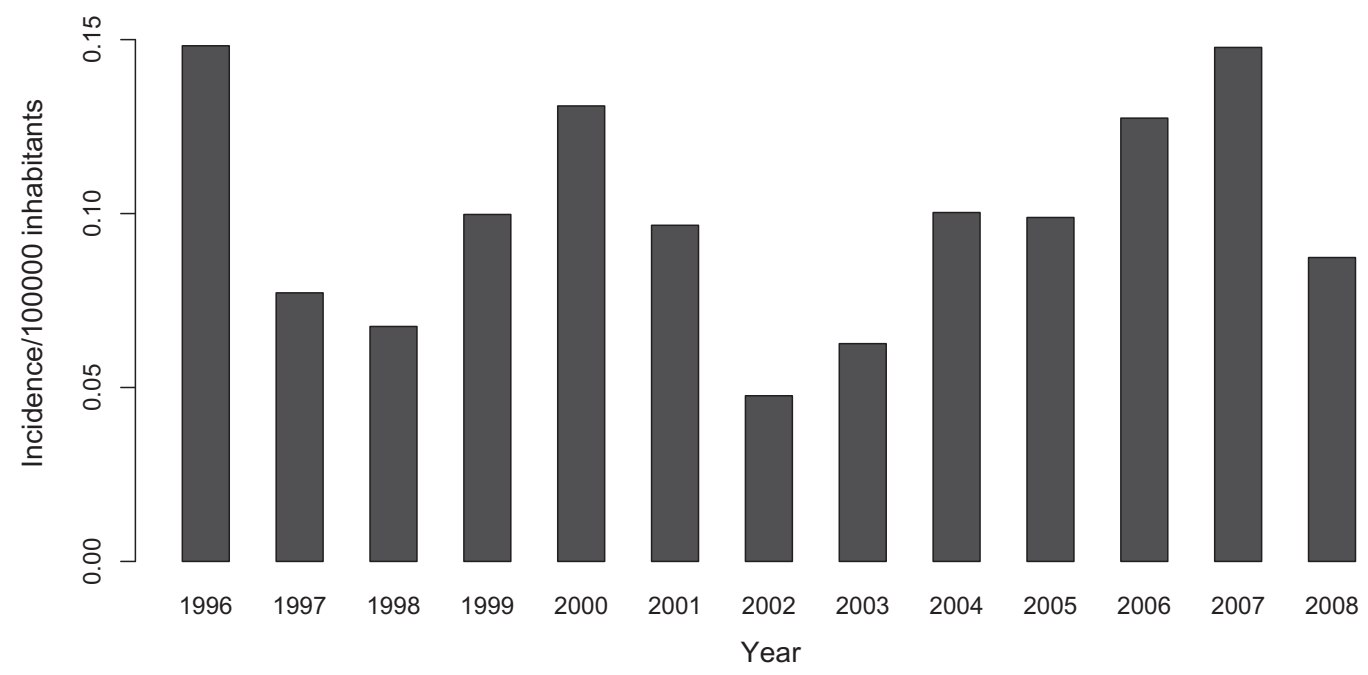

Fig. 1. Incidence of reported cases of human brucellosis per 100,000 inhabitants in Ecuador between 1996 and 2008.

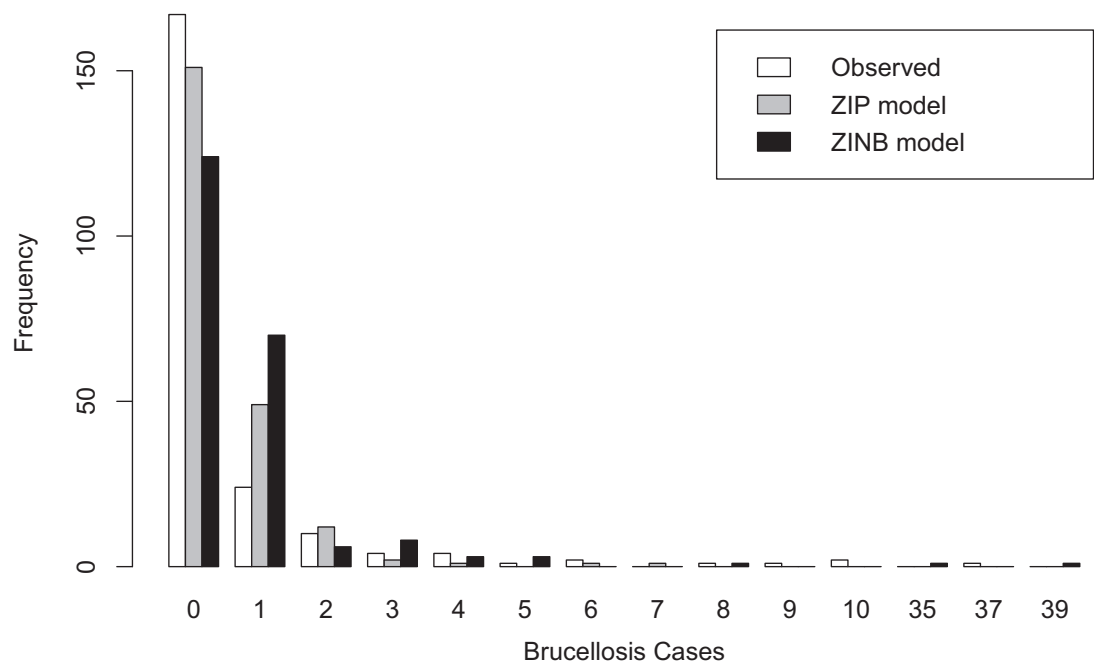

Fig. 2. Distribution of observed reported cases by municipality, expected cases based a zero-inflated poison (ZIP) model and those based on a zero-inflated negative binomial (ZINB) model of human brucellosis in Ecuador between 1996 and 2008. There were 167 municipalities based on the observed data (about 77\%), 151 based on the ZIP model and 124 based on the ZINB model with no reported cases of human brucellosis and the remaining municipalities had between 1 and 39 cases.

in the highlands as compared to those in the tropics keeping all other factors constant. On the other hand, the incidence of reported cases of human brucellosis appeared to increase by a factor of 1.13 with each standard deviation increase in the bovine population whereas the incidence decreased by a factor of 0.77 for each standard deviation increase in the number of sheep.

According to the results obtained from the SaTScan software, there were significant circular space-time clusters with a maximum of $50 \%$ and $25 \%$ of the total centroids included in the scanning window respectively, a maximum of up to $50 \%$ of the study period included and a time precision of 1 year. The results obtained using a maximum of $10 \%$ of the data in the scanning window were exactly the same as those obtained with $25 \%$ of the centroids included in the scanning window. Only the results with $25 \%$ of the centroids included in the scanning window were discussed. The most likely space-time cluster ( $p$-value $<0.001$ ) based on the circular window with $50 \%$ of the centroids in the scanning window spanned the time frame between 2004 to 2008 with 12 human brucellosis cases where only 1 case was expected (Table 2). The relative risk of this cluster was 10.4 indicating that humans in this region are 10 times more likely to get infected with brucellosis as compared to the rest of the study region and time period not included in the cluster. Two significant secondary clusters were also reported with one of the secondary clusters covering about $50 \%$ of the entire study region. This cluster is located in the southern part of the country, near the boundary with Peru. More localized clus- 
Table 1

Parameter estimates, their 95\% confidence intervals and expected incidence of a zero-inflated Poisson model for the number of human brucellosis cases in Ecuador between 1996 and 2008.

\begin{tabular}{|c|c|c|c|c|}
\hline & Estimate & 95\% C.I. & $p$-Value & $\operatorname{Exp}\left(b^{*} s e\right)$ \\
\hline \multicolumn{5}{|l|}{ Count part: Poisson model } \\
\hline Intercept & -4.65 & $(-5.04,-4.27)$ & $<0.001$ & \\
\hline Climatic zone (highlands vs tropical) & 1.00 & $(1.55,1.45)$ & $<0.001$ & 1.64 \\
\hline Number of cattle & 0.000005 & $(0.000001,0.000008)$ & 0.007 & 1.13 \\
\hline Number of sheep & -0.00002 & $(-0.00003,-0.00001)$ & 0.001 & 0.77 \\
\hline Number of goats & 0.00013 & $(0.00003,0.00024)$ & 0.013 & 1.96 \\
\hline \multicolumn{5}{|l|}{ Inflated part: Logistic regression model } \\
\hline Intercept & 1.00 & $(0.25,1.76)$ & 0.009 & \\
\hline Climatic zone (Highlands vs tropical) & 0.58 & $(-0.35,1.51)$ & 0.219 & 1.33 \\
\hline Number of cattle & -0.00003 & $(-0.00005,-0.000003)$ & 0.023 & 0.53 \\
\hline Number of sheep & -0.00002 & $(-0.00006,0.00002)$ & 0.333 & 0.75 \\
\hline Number of goats & 0.0001 & $(-0.00014,0.00033)$ & 0.416 & 1.64 \\
\hline
\end{tabular}

$\operatorname{Exp}\left(b^{*} s e\right)$ : factor change in expected count for a one standard deviation increase in the variable of interest for those municipalities having human brucellosis (Poisson model part) or for those not having the disease (Inflated part).

ters were obtained when only up to a maximum of $25 \%$ of the centroids were included in the circular scanning window. The large cluster previously obtained with the window size of $50 \%$ was observed to dissociate into 4 smaller clusters with a window size of $25 \%$ (Fig. 3). The primary cluster however remained unchanged (Table 2 ).

Fig. 4 shows the map of the cattle density and the significant space-time clusters. It can be seen from the map that cattle were mostly found on the western part of the country. The location of the significant cluster in the northern part of the country was found to coincide with areas of high cattle population density. The significant clusters in the southern and central parts of the country only partially featured in areas with high cattle population density. The low cattle population densities in the eastern part of the country reflect the limited cattle breeding activities in the Amazonia. Just as for the case with cattle, small rumi- nant density seems to be highest in the western part of the country (Fig. 5). However, the significant clusters in the northern, central and southern parts of the country did not coincide with areas of high small ruminant population density. This is an indication that the observed high incidence of human brucellosis maybe due in part to high cattle population density.

The application of the regression tree methodology to study the relationship between the incidence risk of brucellosis and several socio-economic and demographic features of the municipalities revealed that only 5 out of 42 variables play an important role in brucellosis dynamics (Fig. 6). Of these, the percentage of indigenous population appeared to be the most important splitting variable. For municipalities where the percentage of indigenous population was less than 1.5, the incidence risk depended on the density of cattle in the population. When the cattle popu-

Table 2

Characteristics of significant space-time clusters of human brucellosis cases in Ecuador between 1996 and 2008 with up to a maximum of 50\% and 25\% of the centroids included in the circular scanning window respectively.

\begin{tabular}{|c|c|c|c|c|c|c|}
\hline $\begin{array}{l}\text { Window } \\
\text { size (\%) }\end{array}$ & Type & Municipalities & Period & $\mathrm{O}(\mathrm{E})$ & $\mathrm{RR}$ & $\begin{array}{l}p- \\
\text { Value }\end{array}$ \\
\hline \multirow[t]{3}{*}{50} & Primary & Nangaritza, Palanda, Zamora, Loja, Yantzaza, Centinela del Condor, Quilanga & $2004-2008$ & $12(1.2)$ & 10.4 & 0.001 \\
\hline & Secondary & $\begin{array}{l}\text { Aguarico, Cuyabeno, Shushufindi, Sachas, Orellana, Arajuno, Putumayo, Joya de } \\
\text { los Lagoagrio, Pastaza Loreto, Cascales, El Chaco, Gonzalo Pizarro, Santa Clara, } \\
\text { Archidona, Carlos Julio Arrosemena, Taisha, Quijos, Sucumbios, Mera, } \\
\text { Huamboya, Palora, Pimampiro, San Pedro de Huaca, Baños, Bolívar, Pablo VI, } \\
\text { Patate, Cayambe, Santiago de Píllaro, Morona, Pedro Moncayo Rumiñahui, Colta, } \\
\text { Antonio Ante, San Pedro de Pelileo, Latacunga, Espejo, Otavalo, Ibarra, Salcedo, } \\
\text { Cevallos, Sucua, Quito, Chambo, Quero, Mejia, Tisaleo, Logrono, Guano, Mira, } \\
\text { Montufar, San Miguel de Urcuqui, Tiwintza, Riobamba, Saquisilí, Ambato, } \\
\text { Tulcán, Guamote, Cotacachi, Pujilí, Santiago, Sigchos, San Miguel de Los Bancos } \\
\text { Alausí, Sevilla de Oro, Guaranda, Pallatanga, Los Bancos, Penipe, Mocha, Tena }\end{array}$ & $2003-2008$ & $57(27.9)$ & 2.6 & 0.002 \\
\hline & Secondary & Milagro, Yaguachi & 2001 & $5(0.2)$ & 27 & 0.025 \\
\hline \multirow[t]{5}{*}{25} & Primary & Nangaritza, Palanda, Zamora, Centinela del Cóndor, Loja, Quilanga, Yantzaza. & 2004-2008 & $12(1.2)$ & 10.4 & 0.001 \\
\hline & Secondary & Archidona, Quijos, Tena, Carlos Julio Arrosemena, El Chaco & $2007-2008$ & $6(0.2)$ & 32.2 & 0.002 \\
\hline & Secondary & Tulcan & $2003-2008$ & $7(0.5)$ & 14.8 & 0.017 \\
\hline & Secondary & Milagro, Yaguachi & 2001 & $5(0.2)$ & 27 & 0.025 \\
\hline & Secondary & $\begin{array}{l}\text { Chambo, Riobamba, Penipe, Pablo IV, Guamote, Colta, Mocha, Tisaleo, Alausí, } \\
\text { Cevallos, Palora, Pallatanga, Patate, Ambato, San Miguel, Guano, Quero, San } \\
\text { Pedro de Pelileo, Mera, Chimbo, Guaranda, Baños }\end{array}$ & $2003-2006$ & $16(4.0)$ & 4.4 & 0.048 \\
\hline
\end{tabular}

O stands for observed; E for expected and RR for relative risk. 


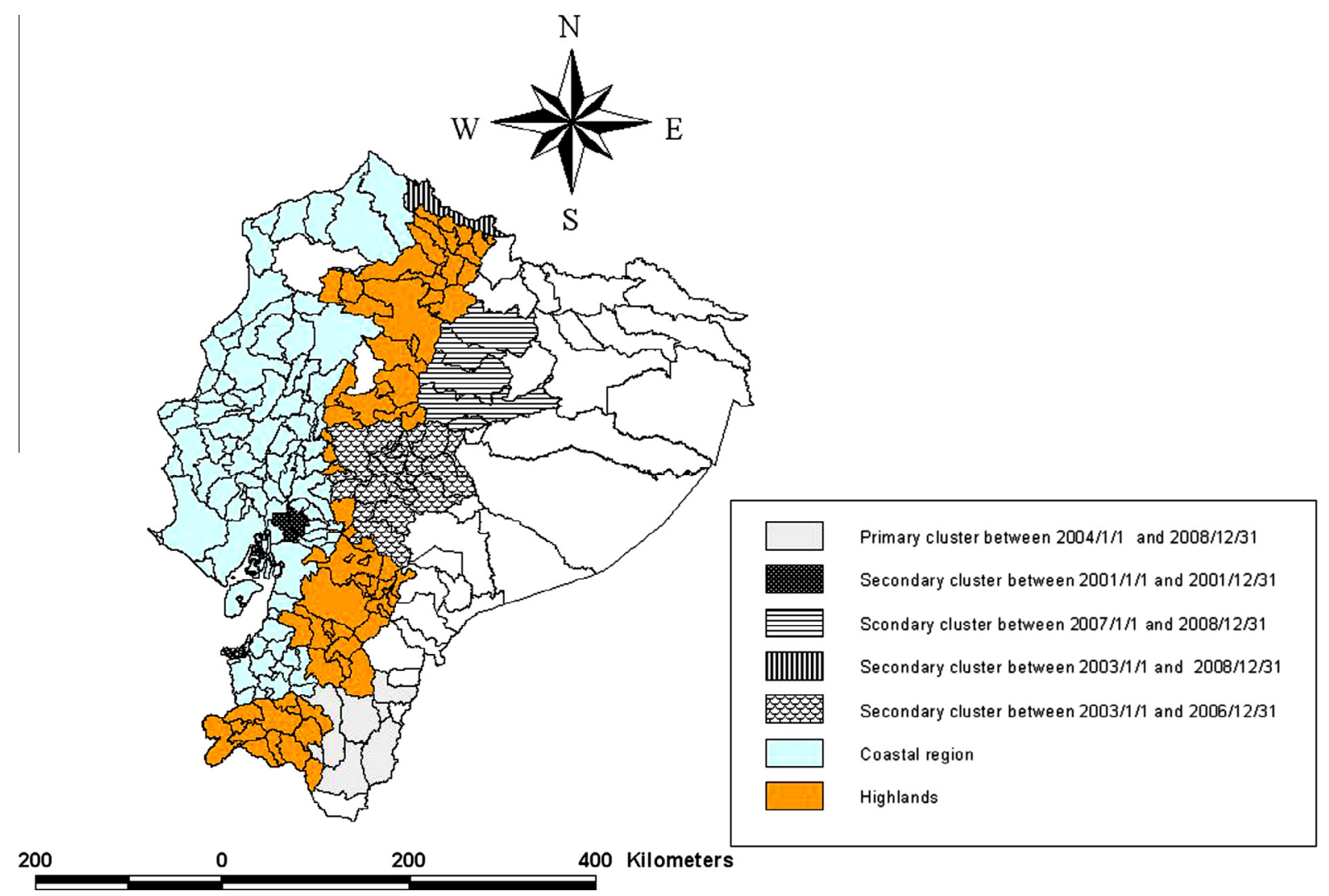

Fig. 3. Significant space-time clusters of human brucellosis cases with a maximum of $25 \%$ of the total centroids used in the circular scanning window between 1996 and 2008.

lation density was greater than 0.57 , the incidence was 3.3 whereas it was 0.54 when the population density was lower than 0.57 . On the other hand, for municipalities where the $\%$ of the indigenous people was greater than 1.5 , the incidence depended on the number of goats in the municipality. When the number of goats was less than 21 , the incidence was 1.7 whereas when the number of goats in the municipality was greater than 21 , the incidence was determined by the number of sheep in the municipality. For municipalities where the number of sheep was greater than 402, the incidence was 7.7. With less than 402 sheep, the incidence was further determined by the proportion of farms with artificial irrigation in the municipality. Municipalities with more than $5 \%$ of the farms with artificial irrigation presented a higher incidence (4.1) as compared to municipalities where less than $5 \%$ of the farms had experienced artificial irrigation (0.3).

\section{Discussion}

In this paper, an analysis of the space-time distribution of human brucellosis cases was performed to identify areas with high risks of the disease. We also investigated the effects of cattle and small ruminant densities on the spacetime distribution of human brucellosis cases. In addition, the effects of socio-economic variables and their interac- tions at the municipality level on the expected incidence of reported cases of human brucellosis were investigated using the zero-inflated Poisson regression and regression tree analyses. The presence of brucellosis among humans may be an expression of a more widespread problem among livestock (Omer et al., 2002; Sauret and Vilissova, 2002; Avdikou et al., 2005; John et al., 2010).

The most significant cluster was observed in the northern part of the Ecuador. It is located in the highlands and at the beginning of the Amazonia region where dairy cattle and sheep are raised. The cluster existed between 2003 and 2008, a time period which coincided with the period of steep increase in the incidence of brucellosis. Parts of this cluster lie in the boundary between Ecuador and Colombia. This cluster should therefore be revaluated in order to confirm the species most frequently found in these areas. This is so because $B$. suis is endemic in Colombia (Arambulo, 1998; Lucero et al., 2008). One of the secondary clusters was located in the southern part of the country bordering Peru. This cluster existed between 2004 and 2008 which also ties with the period of steep increase in the incidence of brucellosis. Given that $B$. melitensis is endemic in Peru (Mendoza-Núñez et al., 2008), the closeness of this cluster to the boundary begs for an investigation of the presence of $B$. melitensis in order to determine whether the increased incidence might have been 


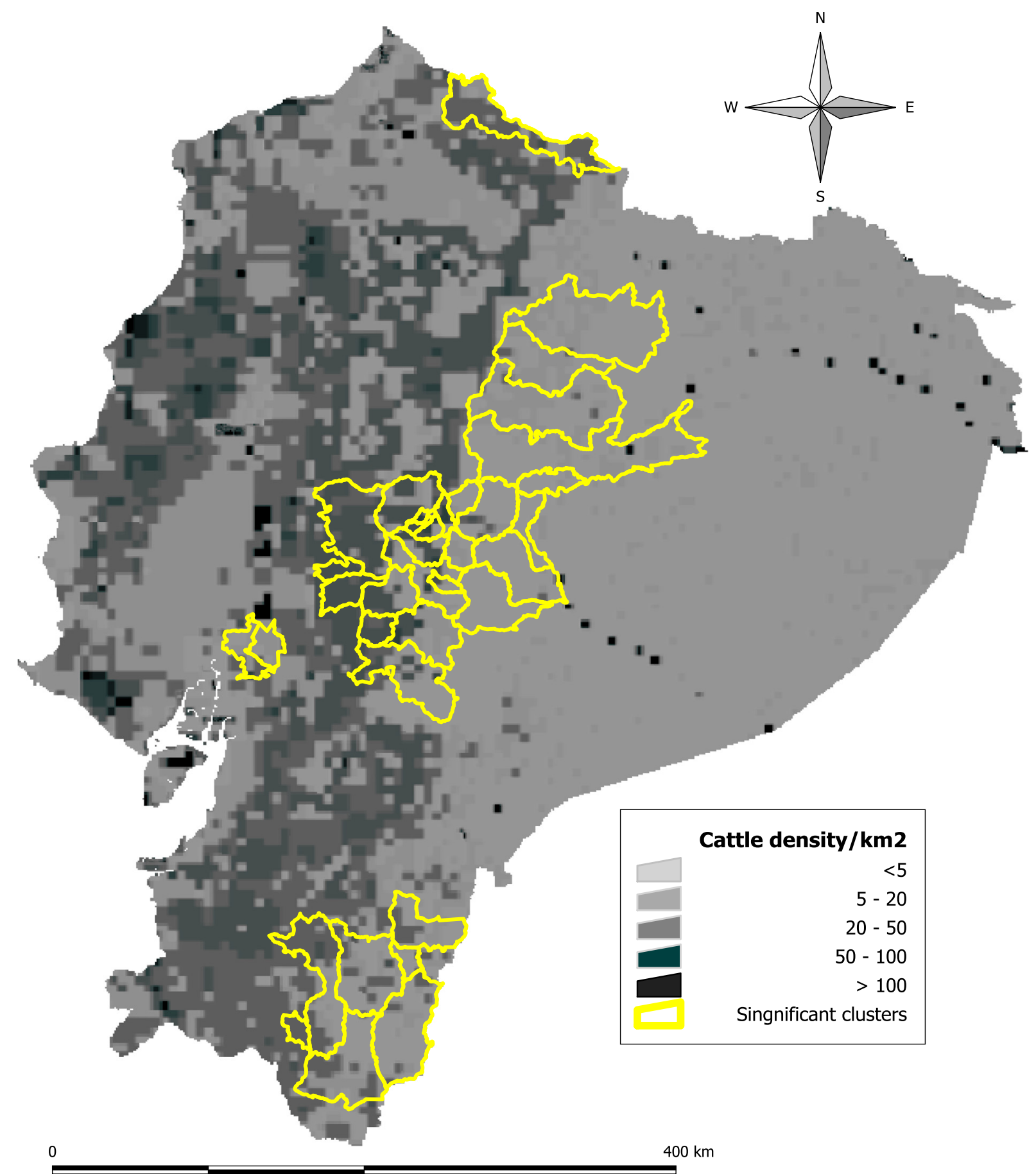

Fig. 4. Possible effects of cattle density on the space time distribution of human brucellosis cases based on circular clusters.

due to transborder infections. Spread of brucellosis across countries has been well documented in places where illicit movements of flocks and of animal products are permitted (Ron-Roman, 2003).

In the Mejia municipality in the South of Pichincha province, the disease in cattle has been considered as endemic for B. abortus, in spite of the continuous vaccination
(Gonzalez, 2003). In this municipality there is at least 1 hospitalized brucellosis case every year. The presence of brucellosis should be confirmed in places where the disease is no longer reported, such as El Carmen in Manabí province, Macara in Loja and Milagro in Guayas Province. Many studies have reported that surveillance in places where the disease has apparently disappeared can indicate 


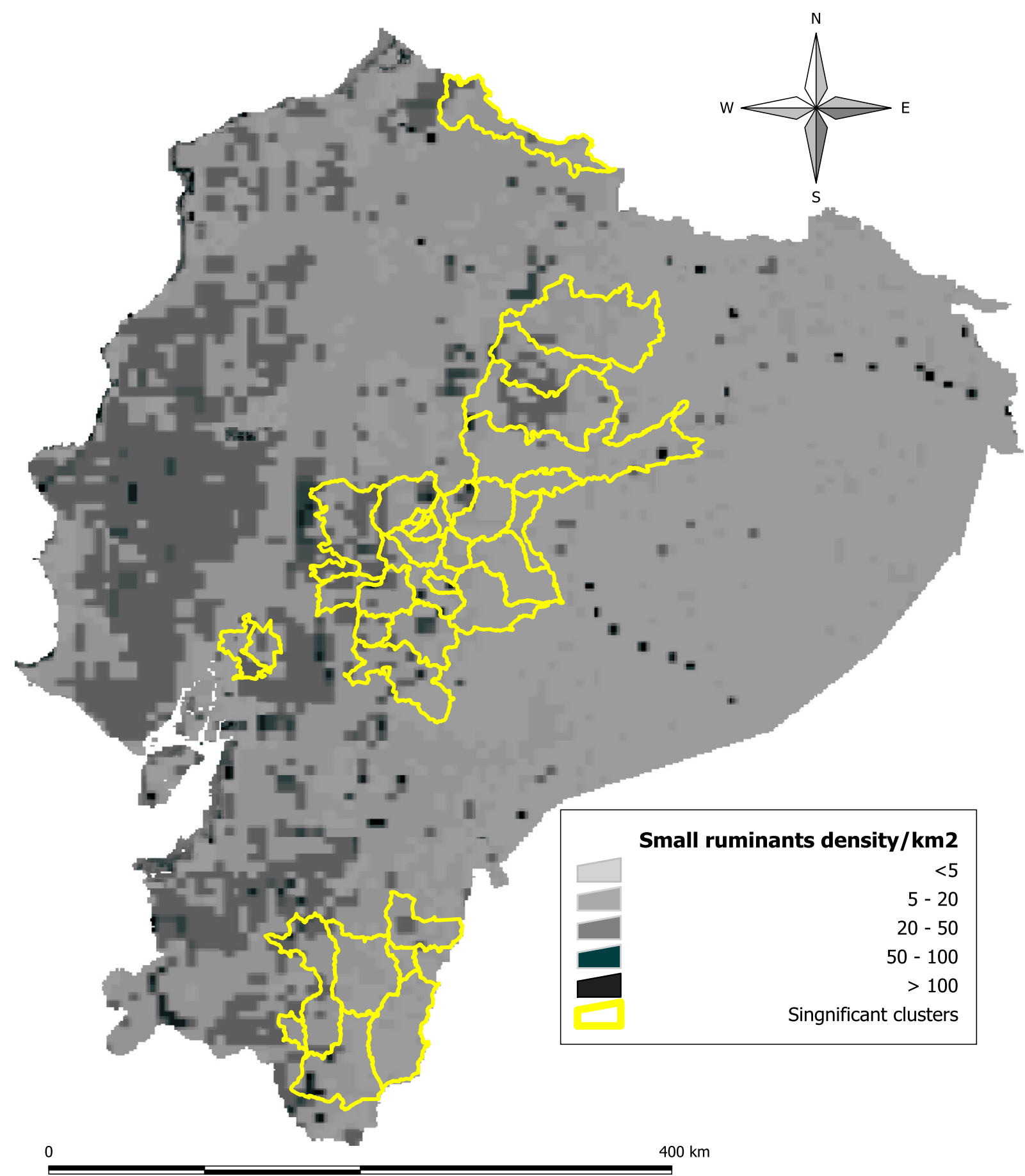

Fig. 5. Possible effects of small ruminant density on the space time distribution of human brucellosis cases based on circular clusters.

sporadic re-emergence (Pappas et al., 2005; Zinsstag et al., 2005; Abernethy et al., 2006). It is important to point out that the rates reported here are based only on hospital cases. As it is known, human brucellosis has a wide spectrum of clinical manifestations, and asymptomatic cases are very common in the acute form of the disease (Sauret and Vilissova, 2002; Gonzalez, 2003; Almuneef et al., 2004; Hasanjani et al., 2004; Cutler et al., 2005). Therefore only a small percentage of the patients go to the hospitals.

There was evidence of a correlation between the significant space-time clusters of human brucellosis cases and the distribution of cattle and small ruminant density. The 


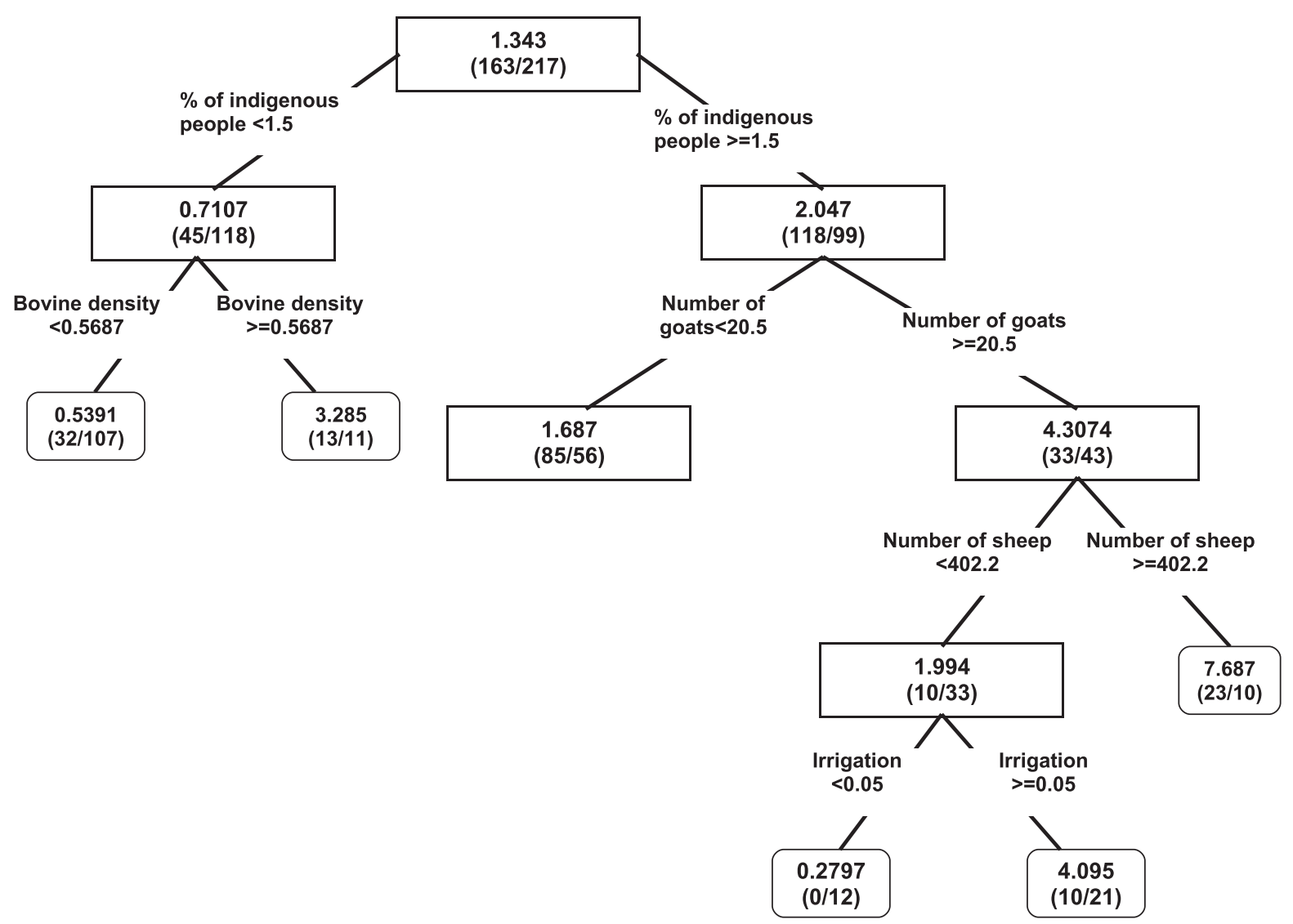

Fig. 6. Regression tree analysis for human brucellosis incidence risk in Ecuador using several socio-economic and demographic variables in 217 municipalities. At each node, the first line represents the incidence per 100,000 inhabitants and the second line represents on the left side the number of human brucellosis cases and on the right side the number of municipalities from the parent node for which the splitting criterion is true.

results from the ZIP model and regression tree analysis further confirmed that cattle and small ruminant density were important factors for the infection. De Massis et al. (2005) demonstrated that in Italy, human brucellosis was more widespread in areas where the prevalence of infection in sheep and goats was highest. Furthermore, using regression analysis they showed that the relationship between human and animal infections between 1997 and 2002 was statistically significant (De Massis et al., 2005). This is therefore an indication that, abating the prevalence in animals will reduce the risk of human infection. The Poisson regression tree analysis also indicated that the percentage of the indigenous population in the municipality was the most important risk factor for human brucellosis in Ecuador. The high influence of this factor is manifested in the dietary habits of the population such as consumption of unpasteurized milk or cheese, and also the type of herd management practices. Other studies have identified the composition of the population as an important risk factor for human brucellosis (Fosgate et al., 2002).

In conclusion, the variations in the incidence rates of brucellosis were clustered in space and time with significant clusters in the northern and southern highlands and parts of the Ecuadorian Amazonia. Customs of people, cattle density, and goat and sheep populations were found to be the main factors influencing the dynamics of brucellosis within municipalities. Since a reduction of the disease in livestock will reduce the incidence in humans (Saegerman et al., 2010), specific programs for prevention, control and eradication such as vaccination should be implemented by national authorities in the livestock production industry in Ecuador. In addition, public sensitization campaigns on the epidemiology of brucellosis should be launched in order to better educate the indigenous population on the epidemiology of the disease and on the risks of consuming unpasteurized milk products. Finally, it is recommended to investigate more suspected brucellosis human cases, especially with blood cultures and subsequent biotyping of Brucella strains to obtain more detailed epidemiological information concerning the circulating Brucella strains among humans in relation with available data among animals.

\section{Conflict of interest statement}

None of the authors of this paper has a financial or personal relationship with other people or organizations that could inappropriately influence or bias the content of the paper. 


\section{Acknowledgments}

This work was supported by the Belgian Cooperation in the framework of the Institutional Collaboration between the Institute of Tropical Medicine in Antwerp, Belgium and the Centro Internacional de Zoonosis in Quito, Ecuador.

\section{References}

Abernethy DA, Pfeiffer DU, Watt R, Denny GO, McCullough S, McDowell SWJ. Epidemiology of bovine brucellosis in Northern Ireland between 1990 and 2000. Vet Rec 2006;158(21):717-21.

Almuneef MA, Memish ZA, Balkhy HH, Alotaibi B, Algoda S, Abbas M, et al. Importance of screening household members of acute brucellosis cases in endemic areas. Epidemiol Infect 2004;132(3):533-40.

Angulo A, Tufiño A. Determinación de la Inmunoprevalencia de Brucella spp. en explotaciones ganaderas de los cantones Santo Domingo y El Carmen [Thesis]. Quito: Facultad de Medicina Veterinaria y Zootecnia, Universidad Central del Ecuador; 2005.

Anonymous. World animal health information database. Technical report. OIE; 2005.

Anonymous. Poblacion Indigena del Ecuador. Technical report. Instituto nacional de Estadisticas y Censos (INEC); 2006

Anonymous. Georeferencion del Agro. Technical report. Division Politico Administrativa del Ecuador; 2007.

Anonymous. Slaughterhouses and National Veterinary Service reports. Technical report. Agencia Ecuatoriana de Aseguramiento de la Calidad del Agro; 2008a.

Anonymous. Indicadores sociales del Ecuador. Technical report. Sistema Integrado de Indicadores Sociales del Ecuador; 2008b.

Anonymous. Geo-network: finding and analysing geo-spatial data Technical report. FAO-AGRA; 2009.

Arambulo P. Brucellosis in the Americas. Technical report. World Health Organization; 1998.

Avdikou I, Maipa V, Alamanos Y. Epidemiology of human brucellosis in a defined area of Northwestern Greece. Epidemiol Infect 2005; 133(5):905-10.

Breiman L. Classification and regression tree. Chapman and Hall; 1984.

Cutler SJ, Whatmore AM, Commander NJ. Brucellosis - new aspects of an old disease. J Appl Microbiol 2005;98:1270-81.

De Massis F, Di Girolamo A, Petrini A, Pizzigallo E, Giovannini A. Correlation between animal and human brucellosis in Italy during the period 1997-2002. Clin Microbiol Infect 2005;11(8):632-6.

DeChello LM, Sheehan TJ. Spatial analysis of colorectal cancer incidence and proportion of late-stage in Massachusetts residents: 1995-1998. Int J Health Geogr 2007;6:20.

D’Orazi A, Mignemi M, Geraci F, Vullo A, Di Gesaro M, Vullo S, et al. Spatial distribution of brucellosis in sheep and goats in Sicily from 2001 to 2005. Veter Ital 2007;43:541-8.

Fosgate GT, Carpenter TE, Chomel BB, Case JT, DeBess EE, Reilly KF. Timespace clustering of human brucellosis, California, 1973-1992. Emerg Infect Dis 2002;8(7):672-8.

Gonzalez P. Seroprevalencia de anticuerpos contra Brucella spp. en pequeños y medianos productores pecuarios y pobladores de dos zonas de la sierra norte ecuatoriana. Bachelor thesis. Universidad central del Ecuador, Facultad de Ciencias Quimicas; 2003.

Hasanjani RMR, Mohrez M, Smailnejad GSM, Soleimani AMJ, Hajiahmadi M. Epidemilogical features and clinical manifestations in 469 adult patients with brucellosis in Babol, Northern Iran. Epidemiol Infect 2004;132:1109-45.
John K, Fitzpatrick J, French N, Kazwala R. Quantifying risk factors for human brucellosis in rural northern Tanzania. PLoS One 2010;5(4).

Kulldorf M. A spatial scan statistic. Commun Statist Theory Meth 1997;26:1481-96.

Lambert D. Zero-inflated Poisson regression, with an application to defects in manufacturing. Technometrics 1992;34:1-14.

Long JS, Freese J. Regression models for categorical dependent variables using Stata. Texas: Stata Corp.; 2001.

Lee BY, Higgins IM, Moon OK, Clegg TA, McGrath G, Collins DM, et al. Surveillance and control of bovine brucellosis in the Republic of Korea during 2000-2006. Prev Vet Med 2009;90(1-2):66-79.

Lithg-Pereira PL, Rojo-Vzquez FA, Mainar-Jaime RC. Case-control study of risk factors for high within flock small-ruminant brucellosis prevalence in a brucellosis low-prevalence area. Epidemiol Infect 2004;132(2):201-10.

Lucero NE, Ayala SM, Escobar GI, Jacob NR. Brucella isolated in humans and animals in Latin America from 1968 to 2006. Epidemiol Infect. 2008;136(4):496-503.

Martins H, Garin-Bastuji B, Lima F, Flor L, Pina Fonseca A, Boinas F. Eradication of bovine brucellosis in the Azores, Portugal-Outcome of a 5-year programme (2002-2007) based ontest-and-slaughter and RB51 vaccination. Prev Vet Med 2009;90(1-2):80-9.

Mendoza-Núñez M, Mulder M, Franco MP, Maas KS, Castañeda ML Bonifacio $\mathrm{N}$, et al. Brucellosis in household members of Brucella patients residing in a large urban setting in Peru. Am J Trop Med 2008;78:595-8.

Omer MK, Assefaw T, Skjerve E, Tekleghiorghis T, Woldehiwet Z. Prevalence of antibodies to Brucella spp. and risk factors related to high-risk occupational groups in Eritrea. Epidemiol Infect 2002;129(1):85-91.

Pappas G, Akritidis N, Bosilkovski M, Tsianos E. Brucellosis. N Engl J Med 2005;352(22):2325-36.

Ron-Roman J. Validación de técnicas diagnosticas para la detección de brucelosis y Estudio epidemiológico en una región andina del Ecuador. Master's thesis. Prince Leopold Institute of Tropical Medicine; 2003.

Rosicova K, Geckova AM, Rosic M, Speybroeck N, Groothoff JW, van Dijk JP. Socioeconomic factors, ethnicity and alcohol-related mortality in regions in Slovakia. What might a tree analysis add to our understanding? Health Place 2011;17(3):701-9.

Saegerman C, Berkvens D, Godfroid J, Walravens K. Bovine brucellosis. Infectious and parasitic disease of livestock. Editions Tec et Doc Lavoisier, France; 2010. p. 971-1001.

Sauret JM, Vilissova N. Human brucellosis. J Am Board Fam Pract 2002;15(5):401-6.

Sewell MMH, Brocklesby DW. Animal diseases in the tropics. 4th ed. London: Bailliere Tindall; 1990.

Terneau TM, Atkinson EJ. An introduction to recursive partitioning using the RPART routines. Technical report. Rochester, MN: Mayo Foundation; 1997.

Torres H. Control de Brucelosis bovina - programa nacional. Ministerio de Agricultura, Ganadería, Acuacultura y Pesca (MAGAP), Servicio Ecuatoriano de Saniadad Agropecuaria (SESA). Quito, Ecuador; 2008 30

Yamamoto T, Tsutsui T, Nishiguchi A, Kobayashi S. Evaluation of surveillance strategies for bovine brucellosis in Japan using a simulation model. Prev Vet Med 2008;86(1-2):57-74.

Zaninotto P, Falaschetti E. Comparison of methods for modelling a count outcome with excess zeros: application to Activities of Daily Living (ADL-s). JECH 2011;65(3):205-10

Zinsstag J, Roth F, Orkhon D, Chimed-Ochir G, et al. A model of animalhuman brucellosis transmission in Mongolia. Prev Vet Med 2005;69(1-2):77-95. 